\title{
Persuasive Argument as a Determinant of Group Polarization: A study of Selected Kenyan Secondary School Disciplinary Panels
}

\author{
Peter J.O. Aloka \\ University of the Western Cape, South Africa \\ E-mail:jairopeteraloka@yahoo.com \\ Olaniyi Bojuwoye \\ University of the Western Cape, South Africa \\ obojuwoye@uwc.ac.za
}

Doi:10.5901/mjss.2014.v5n10p348

\begin{abstract}
The study investigated whether persuasive arguments in the dynamic interactions among disciplinary panel members influenced the decision making leading to group polarization among members of selected secondary school disciplinary panels in Rongo district of Kenya. The study adopted a qualitative approach and within which a phenomenology design was used. The population for the study comprised all Kenyan schools with behaviour management practices and School Disciplinary Panels. Ten schools were involved and a sample of ten participants selected from co-educational $(n=5)$, boys only $(n=3)$ and girls' only $(n=2)$ schools participated in the study. Data was collected using interview protocol and analyzed using the thematic framework. The study found out that, the persuasive arguments among panel members during the disciplinary hearing deliberations influenced the panel members to make good quality group decisions. It was recommended that, disciplinary panels should be broad-based, and that, there should be some form of checks and balance in the operations of school disciplinary panels in order to avoid inaccurate decisions that may occur from negative effects of persuasive arguments.
\end{abstract}

Keywords: persuasive arguments, group polarization, decision making, Kenyan secondary schools, student behaviour

\section{Introduction}

Behaviour problems have been on the rise in Kenyan schools for some time now (Aloka, 2012). Some of the various maladaptive behaviours found among Kenyan school children include bullying, vandalism, stealing, alcohol and drug abuse, truancy, not completing homework assignments and other forms of problem behaviours (Aloka \& Bojuwoye, 2013). These problem behaviours impact negatively on the teaching and learning enterprises of schools as well as on the safety and security of the school environment (Aloka, 2012). Moreover, it has been found out that maladaptive behaviours of students are associated with their social adjustment and academic performance and therefore, could affect their success in school and later in life (Hinshaw, 1992). The behaviour problems of students may impact negatively on the students themselves; affect not only the other students in school, but also the teachers and the school environment as a whole. In response to the challenge, Kenyan schools have developed student behaviour management practices aimed at addressing student problem behaviours. Schools' student behaviour management practices including policies on student behaviour expectations, school rules and regulations as well as counselling services are all to be coordinated by each School Disciplinary Panel (Aloka, 2012).

A School Disciplinary Panel is to be composed of small group of teachers as a way of emphasizing the latter's roles in student behaviour development and not just student academic or educational development (Aloka, 2012). Each Kenyan secondary school disciplinary panel is made up of between 8 to 10 members on average, though the number may be bigger or smaller depending on the number of teachers in a given school (Aloka, 2012). Disciplinary hearings thus appear to be a typical small social group processes and are expected to incorporate dynamic interactions among panel members, as they discuss disciplinary problems of students that should lead to group decisions rather than individually made decisions. The disciplinary panel decisions concerning behaviour problems of students are made after the panel members have studied the case at hand well enough and sought the opinions of other group members, considering the factors including, the professional demands and school management expectations (Aloka, 2012). Disciplinary panel members are guided by the terms of references which are sets of expectations for appropriate responses to students' maladaptive behaviours. These terms of references guide the panel members' behaviours including the roles and 
responsibilities members are to play in order for the panel to accomplish what is expected of it. The terms of reference for the disciplinary panel serve as goals which guide members' behaviours in terms of roles and responsibilities leading to decisions of the panel (Aloka \& Bojuwoye, 2013). The immediate goal is to provide appropriate response to student disciplinary problems being treated by the panel. The long-term goal is the contribution to the overall development of students in the school.

The behaviours of panel members can also be attributable to the individual panel members' exposure in a group setting to dimensions which are considered to be more persuasive (Straus, Parker \& Bruce, 2011). This can influence the group members to shift from their individual opinions and decide to go along with the group (Baron, 2005), a phenomenon known as group polarization. During group deliberations, the members can exchange arguments amongst themselves as they make decisions concerning the students' behaviour problems. The panel's decisions emanating from the dynamic interactions during disciplinary hearings, lead to initiation of appropriate interventions in problem behaviours being addressed. This means that, disciplinary panels operate like small social groups, and the dynamics of disciplinary panels seem to be similar to those of small social groups. If this assumption is the case, then it would be interesting to explore disciplinary hearing process to understand the nature of dynamic interactions among members.

The concern of this study was therefore to explore whether persuasive arguments in the dynamic interactions among disciplinary panel members influenced their decision making leading to shifts from pre-disciplinary hearing individually made decisions to post-disciplinary hearing group decisions (group polarization).

\section{Literature Review}

This section looks at literature on aspects such as group polarization, persuasive arguments and previous studies that have been done.

\subsection{Group Polarization}

In any social group, the assumption is that members would hold individual pre group meeting opinions or decisions about the issue to be discussed in the group meeting. Klein and Olbrecht (2011), describe group polarization as a process where group discussion tends to intensify convergence of group opinions. According to Meyers (1989), Kim and Park (2010), group polarization is the result of shifts to group decisions from individual members' pre-group decisions concerning the group task. The concept of group polarization has conspicuous importance to the small social groups like the disciplinary panel group in secondary schools that make decisions on the students' behaviour problems. With regards to the context of this study, group polarization can be defined as the tendency of disciplinary panel members to shift towards consensus in their decisions at the close of a group meeting, the position which may be different from which an individual held before the disciplinary hearing meeting. To fulfil the task of the group, consensus has to be reached on student behaviour problems or on the management of student behaviours.

Decisions that result from group polarization may be regarded as risky/extreme or cautious (Sobel, 2006). Risky or extreme decisions are those decisions on the behaviour of the student which could threaten the student's dignity, safety and fundamental rights (Joubert, de Waal \& Rossouw, 2004). These risky decisions can result due to group think (Boateng, 2012) which occurs when members only seek harmony among themselves ignoring better alternatives to address a disciplinary problem. The risky decisions may lead to adverse or negative actions of the school authorities which may not promote the positive growth and development of the students but actually could be detrimental. On the other hand, cautious decisions are decisions which take into consideration the student's dignity, safety and fundamental rights in any action to be taken against the misbehaving student. Cautious decisions take into consideration extraneous circumstances surrounding the misbehaviour and avoid acts which may prevent the positive growth and development of the student. Cautious decisions are also more likely to be beneficial and promote the growth of the offender (s) (Conkle, 2007). Moreover, cautious decisions promote best ways of seeking alternatives to how best to manage the students' behaviour problems, to enhance their development rather than retarding it.

One negative consequence of group polarization occurs when individual make risky decisions. This may result because individuals in a group sometimes do not feel as much responsibility and accountability for the actions of the group as they would if they were making the decision alone. The panel members may have a feeling that they have less personal responsibility for the negative consequences of such a decision within the group setting (Zorn, Roper, Broadfoot \& Weaver, 2006). With regard to the disciplinary panels, at times certain panel members may hide within the group when making contributions to panel decisions; hence they can take greater chances because they feel they are less likely to be blamed. 


\subsection{The influence of Persuasive arguments}

Group dynamicists such as Isenberg (1986), Sunstein (1999) and Brown (2000), have attempted to explain the mechanisms of group polarization. The Persuasive Arguments Theory explains the dynamic interactions in a group process leading to group polarization. The Persuasive Arguments Theory suggests that individuals freely exchange arguments that are available to them during group discussions (Zhu, 2009). When an individual hears one or more colleagues" arguments, the individual's thinking is likely to be shifted or realigned towards the arguments of the other colleagues in the group. Prior to the group meeting, different individuals may recall different arguments from a larger culturally available pool and formulate different positions, depending on the number and persuasiveness of the arguments that were available to them prior to the group meeting. Since supportive arguments available to each member of the group prior to the group meeting may not be evenly distributed among all the members of the group, the group members tend to learn from the discussion about additional arguments that support individual group members favoured position. Group members have different roles to perform, some of which relate to helping the groups perform its tasks, and others relate to maintaining the group and building cohesive relationships among members. Some of the member roles in small social groups like the disciplinary panels include - initiating, contributing or giving information or opinion, some other members may be seeking information or opinion while others coordinate others opinions. Some members of a group may also play the role of summarizing, clarifying, elaborating or evaluating opinions while others encourage others, or comprise with others (Belbin, 2010). The proponents of this view have realized that group members are influenced by the novelty or validity of arguments presented by the other members. The factors such as a person's expertise, trustworthiness, attractiveness, likeableness, power, gender, age, position, years of teaching experiences and status can affect the likelihood that a message will be scrutinized (Olson \& Wells, 2004).

However, within the disciplinary panels, the information in the persuasive arguments can, at times, be biased, because certain panel members emphasize position-consistent arguments in group discussions and avoid expressing counter arguments so that they can present the self favorably and confidently before other group members (Vohs, Baumeister \& Ciarocco, 2005). Furthermore, as the disciplinary hearings reveal the prevailing position concerning a behaviour problem being supported by most group members, some members may avoid expressing concerns about the prevailing position because of social risks of voicing minority opinions (Bassili, 2003). This eventually, makes such group members to shelve their opinions and shift their decisions to those of other members.

\subsection{Previous studies}

Research on the influence of persuasive arguments on group polarization has been documented. Most studies reported have been carried out in laboratory settings, hypothetical situations and few reported in educational settings. Moreover, a review of literature indicated that there was very scanty information regarding the phenomenon being investigated in school disciplinary panels. Meyers' (1989) study actually tested the predictive validity of persuasive argumentation with regards to the shift in group decisions. The findings indicated that, the discussion arguments were found to have increased the shifts in decisions after group discussions. Zuber, Crott \& Werner, (1992) study reported that after arguments shared among group members the final group decisions showed a shift toward more extreme decision (3.39 vs. 3.59, $P<0.05$ ), from the pre-group decisions, leading to group polarization. Tormala, Briñol \& Petty, (2006) also found out that, the credibility of message determined how the message would be perceived by the people, for example, participants had greater confidence in their thoughts after learning that the source was high rather than low in credibility. Wayne's (2011) study reported that, the credibility of group members influenced the participants to change their decisions after group deliberations. Etienne, Korzilius, Vennixa \& Jacobs, (2011) study corroborated that, persuasive messages during group discussion influenced shifts in beliefs and attitudes of the participants. Tajeddin, Safayeni \& Connellys' (2012) study, add that, the emergence of expert recognition at the group level shifts the balance of individual influence on the group decision in favour of the expert. Moreover, the Albarracina, Wallaceb, Hartc, \& Brownds' (2012) study also confirmed that persuasive arguments based on new information influence shifts from pre-group individually made decisions to post-group decisions. Studies have also shown that, group members might also make more cautious decisions (Nordhoy, 1962). According to results of studies (Nordhoy, 1962; and Stoner, 1968), the group effects were not consistent for all the 12 items used by Stoner. A review of results presented from Stoner's thesis indicated that, on one item that dealt with marriage, Stoner"s subjects were consistently more cautious in their post-group decisions. The findings, based on studies carried out by other researchers such as Rabow, et al, (1966) and Stoner, (1968), have reported that groups shift toward cautious decisions.

From the above reviewed studies on the influence of persuasive arguments on group polarization, it can be 
observed that, most of them adopted quantitative approaches with large sample sizes that enhanced generalizability of their findings. However, the qualitative component to reveal the verbal experiences of the participants regarding the dynamics in the group interactions was lacking. Therefore, the current study filled this gap by bringing in the qualitative component which led to more comprehensive results on the phenomenon being investigated. Finally, no study was found in the literature that specifically focused on investigating the influence of persuasive arguments on group polarization in disciplinary hearing process.

The current study was designed to ascertain whether or not persuasive argument influenced group polarization among panel members during school disciplinary hearing processes.

A research question was advanced to guide the study:

Are there polarizing effects of persuasive arguments in decision making behaviours among members of selected secondary school disciplinary panels in Rongo district, Migori County of Kenya?

\section{Research Methodology}

\subsection{Research Design}

The study adopted a qualitative approach, within which the phenomenological design was adopted. The participants of the study reported on their experiences of the influence of persuasive arguments on group polarization during disciplinary hearings.

\subsection{Participants}

The study was limited to ten selected secondary schools in Rongo district of Kenya. The district has three categories of secondary schools, namely, Boys' Only, Girls Only and Co-educational schools. The population of the study comprised secondary school teachers in Rongo district, Migori County of Kenya, who were members of disciplinary panels in their respective schools. A sample size, (n) of ten (10) panel members was selected for interviews using the purposive sampling technique. According to Teddlie \& Yu (2007), purposive sampling techniques are primarily used in qualitative studies and may be defined as selecting units (e.g., individuals, groups of individuals, institutions) based on specific purposes associated with answering a research study's questions. The sample size of ten panel members for interviews was considered to be adequate, for the current study because for the phenomenological studies, sample size recommendations range from 6 to 10 for qualitative research (Mason, 2010). When selecting the ten teachers, the panel members of different age groups, both male and females, young and old in age, least experienced to more experienced, some from the co-educational, boys' only, and girls' only schools were sampled.

\subsection{Measuring Instruments}

The researcher used semi-structured interviews to collect data. According to Babbie \& Mouton (2001), the qualitative interview is conducted to elicit information that cannot be observed, and to get the feelings, thoughts, and the meanings that people attach to events. Interview process-allows the researcher to observe and ask questions, thus providing opportunity to look at issues as if through the eyes of the participants (Bojuwoye \& Akpan, 2009). Trustworthiness of the data obtained was ensured by researcher employing the peer scrutiny of the research by colleagues, peers and academics, as well as feedback offered to the researcher at conference presentations. In addition, the researcher employed the examination of previous research findings to assess the degree to which the study results are congruent with those of past studies.

\subsection{Procedure}

Permission to conduct the study was obtained from the University of the Western Cape Research Ethics Committee, Ministry of Education Kenya, the principals and teachers of the ten participating schools in Rongo district, Migori County of Kenya. Upon arrival at the schools, the researcher explained to the disciplinary panel members the aim of the study. At the beginning of the interview sessions, the participants were told about the study, and requested volunteers to be interviewed. Participation was voluntary and the participants were assured about confidentiality, anonymity and were told that they could withdraw their participation at any time if they were not comfortable with the interview sessions. Upon obtaining permission from the selected participants, the interview sessions were recorded using a digital tape recorder. 
The disciplinary panel members then went to begin their usual hearings, and at the end of the disciplinary hearing meetings, the researcher interviewed panel members purposively selected. The interviews were done in a separate room where the participants were free to give their views. A total of 10 panel members were interviewed, with a participant sampled from every school disciplinary panel selected. The researcher interviewed the selected participants on their feelings and experiences concerning the influence of persuasive arguments on group polarization during disciplinary hearings as were guided by the interview schedule. Each of the interview sessions lasted about 30 to 45 minutes, thereafter, the participants was given an opportunity to ask questions.

\subsection{Data Analysis}

The thematic framework was used to classify and organize data according to key themes or emergent categories (Ritchie \& Lewis, 2003). The researcher first became familiar with the data and also gained an overview of the data. This was done by reading and re-reading the interview transcript several times. The transcripts were then summarized, the emerging patterns then organized into categories or basic descriptive meaning units common to all the participants. From these meaning units, themes were derived. Measures were taken to ensure that these themes captured the essence of various aspects of participants' experiences of the dynamic interactions of the disciplinary hearing group processes. The emerging themes from the data analysis were with regard to the meanings and or the interpretations participants gave to their experiences of the dynamics of disciplinary hearings particularly in terms of how persuasive arguments in the disciplinary hearing group processes which might have influenced their decisions or the shifts from their pre disciplinary hearing decisions to their post disciplinary hearing decisions (group polarization). The results also took into consideration types of decisions - cautious or risky decisions.

\section{Findings and Discussions}

The results of the study reported that there were shifts from cautious to risky decisions and vice versa.

\subsection{Results on the persuasive arguments and shifts from pre disciplinary hearing cautious to post disciplinary hearing risky/extreme decisions}

Persuasive arguments as a consequence of new information that was available to panel members at the disciplinary hearing can influence group polarization. With regard to shifts from cautious pre-disciplinary hearing decisions to extreme or risky post-disciplinary hearing decisions, was the case of a school girl accused of unauthorized absence from school. During disciplinary hearing, new information available to members was that this misconduct of the girl has been reported several times as the housemaster offering information on the girl to the panel stated that, the girl had been given several warnings to desist from the misconduct. Thus, at the disciplinary hearing when panel members came to understand that the student was a habitual offender, they took a harsher position. Thus, many panel members who originally had decided to overlook the offence thinking it was a once-off affair changed their cautious decisions to more risky decisions in an apparent indication of the need to punish such behaviour as stipulated in the school policy. Since the school rules and regulations stipulate that unexcused absence from school or classroom should not be tolerated, members opted to implement the strict policy which makes the school to be seen as playing its monitoring and supervision role and one that does not tolerate indiscipline on the part of students.

An excerpt from interview transcripts reflecting the view of a participant is as follows:

The new information about the girl helped me to see her as rather very in-disciplined, and therefore I agreed with the other panel members that the misconduct was unacceptable and deserved to be punished. I considered the information presented to be true especially coming from the housemaster who looked after the students. Moreover, I agreed with other members of the disciplinary panel that such misconduct should not be allowed in the school. I was persuaded by the new information and therefore aligned myself with other members who were concerned about the negative effect of such misbehavior on the discipline tone of the school. This is responsible for my change in decision about the problem.

Another disciplinary problem brought to disciplinary hearing which also resulted in the shifts from pre-disciplinary hearing cautious decisions to post-disciplinary hearing risky decision was that of a drunken student. According to school's policies on alcohol or drug abuse, this is unacceptable because such behaviour makes school environment unsafe for both students and teachers. A drunken student is not only a danger to him or herself but to other students as he or she 
may engage in violent behaviour like fighting or physical assault, vandalism or damage to properties as well as other forms of abuse which can cause injuries, health problems or even death. Moreover, drunken students are unlikely to maintain regular school attendance, and therefore, perform rather very poorly academically. The participants indicated that, prior to the disciplinary hearing meeting, when they were considering the misconduct individually, some panel members did not consider the problem as very serious that, probably it was an isolated case, on one of those little pranks students play and, therefore, decided that the boy only needed to be warned. At the disciplinary hearing meeting, the school security officer was invited to share more information on the student's misconduct. He provided new information to the effect that the boy was often seen to be extremely drunk, and incapable of controlling himself, as his walking was wobbling and fell several times. He also pointed out that the bruises on parts of the body of the boy were results from the falls.

With the new information, the panel members were persuaded to change their previous decisions about the misconduct. The panel members shifted their opinions because the new evidences provided by an eye-witness during the disciplinary hearing indicated that, there was risk to life and properties and as such, the behaviour was unacceptable as it made school environment unsafe and hampered students learning. However, the panel also decided that there should be a general public education on alcohol abuse for all students organized by the school guidance and counseling department.

An excerpt from the interview of a participant indicating this shift in decisions from pre-disciplinary hearing individual cautious decision to post-disciplinary hearing risky decisions is:

The new information that the security officer who witnessed the incident gave us in the disciplinary hearing made me to change my decision. From his statement, the boy was guilty of the two offences committed, that is, consuming alcohol in school and interfering with other students as well. My final decision after the meeting changed because I agreed with other members of the panel particularly regarding their concern for the negative impact of alcohol abuse on the school disciplinary tone.

Credible information, on the basis of evidences regarding a disciplinary problem committed, influenced shifts in decisions among the panel members due to the negative effect of the problem on the disciplinary tone of the school, the fact that behaviours were unacceptable, and possible harm of the disciplinary behaviour on other students as well as resulting in unsafe environment of the school. Fraudulent behaviour as in falsifying information by students was another case in which credible information by an expert persuaded disciplinary panel members to arrive at group decisions different from pre-disciplinary hearing individually made decisions. A case of forged bank deposit slip for payment of school fees was reported. The school bursar and a bank clerk testified to the effect that the deposit slip presented by the student as evidence of payment of school fees was forgery, as the two experts clearly showed how the slip had been cleverly altered. This information from the evidences produced, influenced the panel members to shift their decisions from the pre-disciplinary cautious to post-disciplinary risky decisions. The final panel decision was that the boy had to be sanctioned because it was considered that forging is a serious criminal offence that cannot be tolerated in school.

An excerpt from interview transcripts is as follows:

At first I thought, and decided that we could look for other means of handling the problem. However, my decision changed when the forged receipts were produced at the meeting and I confirmed that the boy was guilty of the offence after having seen the forged receipts brought by the bursar. I could not doubt it anymore because the evidence gave us proof that it was actually true that the forgery had been committed. I therefore, aligned my decision with those of the other panel members because of the credibility of the evidence provided. The boy had to be sent home because it needed to serve as a lesson to other students to desist from committing such vices.

From the results presented above, shifts from cautious pre-disciplinary hearing decisions to risky post-disciplinary hearing decisions occurred when the panel members felt that the new information revealed that not intervening to stop the misbehaviour immediately could badly damage the school's image. The new information also revealed that serious harm had been committed; it badly affected the victims and put the school in an unsafe environment for teaching and learning. The panel members also shifted to risky decisions because the new information influenced them to harden their position on the disciplinary problem. For example, when there was need for firm actions, especially, when new information revealed that offender was habitual, and when there was danger and possible harm to the offender or other students. Risky decisions were also made when the panel members felt that the disciplinary problem should not be tolerated. For example, in instances when the behaviour problems were unacceptable, as indicated in the school rules and regulations that students should not engage in such behaviours, like stealing, bullying, fighting, cheating, or violent 
acts like stabbing, and shooting. In such cases, the panel members tended to shift to risky decisions. Finally, the panel members shifted to risky decisions when the problem impacted negatively on the school disciplinary tone and can embarrass the school or seriously damage the schools' image or reputation.

The persuasive arguments occurred when new information is provided or when the person providing new or extra information is considered to be an expert and perceived to be providing valid or true information. The new or valid information helped the disciplinary panel members to arrive at decisions leading to intervention which is in the best interest of the student concerned and which can best address disciplinary problems and facilitate positive behavioural development. This finding is consistent with El-Shinnawy \& Vinzes', (1998) study that, individuals share relevant and factual information during group discussions and that, the other group members offer information or opinions helping an individual to view a situation from completely a new perspective from the one the individual previously held. Similarly, Meyers' (1989); Zuber, et al, (1992); Tormala, et al, (2006); Tormala, et al, (2007);Wayne's (2011);Etienne, et al, (2011); Tajeddin, et al, (2012); Andiliou, et al, (2012); Li Lu \& Poppy, (2012) and Albarracina, et al, (2012) all confirm that information shared in a group and perceived as novel or new, original, valid or if the information is perceived to be true and credible, is more likely to influence the opinions of group members about the issues being discussed leading to group polarization.

The results also indicated that panel members reported shifts from pre-disciplinary hearing risky to post-disciplinary hearing cautious decisions.

\subsection{Results on Persuasive arguments and shifts from pre-disciplinary hearing risky to post-disciplinary hearing cautious decisions}

Persuasion as a consequence of new information may not always make panel members to shift from cautious predisciplinary hearing decisions to risky post disciplinary hearing decisions as previously discussed above. Sometimes, it could be the other way round. Data analysis revealed that in some disciplinary hearing cases, the panel members reported shifts from their original extreme or risky pre-disciplinary hearing decisions to cautious post-disciplinary hearing decisions. Schools' disciplinary panels have a responsibility of enhancing positive behaviour management aimed at promoting appropriate behaviour and developing self-discipline and self-control in students (Joubert, et al, 2004). In performing the above role, and depending on the behaviour problem presented during disciplinary hearing, panel members were persuaded to shift from their original risky pre-disciplinary hearing decisions to cautious post-disciplinary hearing decisions so that their role in the behaviour development of students would not be counter-productive. Moreover, in these instances, the panel members made cautious decisions to prevent further damage to the students caught with behaviour problems.

Participants reported on a disciplinary problem presented at a disciplinary hearing which led to shift in decisions because of the type of disciplinary problem. A male student was accused of excessive aggressive behaviour leading to fighting with other students. In the school's rule and regulations, fighting is considered a violent behaviour with possibility for harming people and making the classroom learning environment less conducive. Aggressive behaviour also makes people fearful and impact negatively on the safety and security of the school. Severe consequence of fighting among students in schools includes interference with the normal learning activities of students. Weapon used for defensive purposes on school grounds, can cause serious injury to students resulting to medical expenses of treatment and absenteeism from school (Rudatsikira, Muula \& Siziya, 2008). Fighting is therefore, regarded as a sign of poor behaviour development. Sanctions prescribed in the schools' rules and regulations for such related offences include suspension from school and in extreme cases of grievous bodily harm, this may even lead to expulsion from school. Therefore, it could be understood why members would take extreme position in their pre-disciplinary hearing opinions on fighting by students.

However, in the case reported on, during disciplinary hearing, the new information revealed several dimensions of the problem and particularly the circumstances which may have led to the problem. The new information made panel members gain better understanding of underlying circumstances responsible for the students' behaviour problems. The panel members were informed that the boy had lost both parents in a road accident, a situation which would have affected his emotions. Panel members were generally sympathetic and were persuaded to shift from their original individual risky pre-disciplinary hearing decisions to cautious post-disciplinary hearing decisions to assist the offender to develop appropriate behaviour and values. The option of decision to send the student home was viewed by the panel members as counter-productive as this could destroy him completely. There did not appear to be a real home to send the student to as there was no parental support which could be sought in addressing the problem. Suspending the student was more likely to mean turning him loose into the streets for further risky behaviours. The panel therefore, resolved that 
the school has responsibility to play the role of the home here and therefore, took decisions to enable the school alone to manage the misbehaviour.

Excerpt from interview transcript regarding a participant's response is as follows:

Initially, I decided that the boy would have been suspended as is indicated in the school policy. But my decision changed when we were informed that the student was an orphan having lost both his parents during a ghastly motor accident in which he was also involved. His aggressive behaviour was perceived by panel members to possibly be as a consequence of the tragic loss of his parents. Some panel members offered opinions that what the student needed was understanding and sympathy.

In certain instances, the new information from the offenders during the disciplinary hearing hardened the panel members' opinions and did not result in shifts in decisions. Considering the type of the problem committed by the offenders, the panel members stuck to decisions which they considered to be in keeping with zero tolerance policy of the school on such misbehaviours. For example, when the offenders were seen as not indicating willingness to reform from their misbehaviour, the panel members tended to harden their positions, in order to convey their firmness on adopting appropriate behaviour as expected.

Shifts from pre-disciplinary hearing risky decisions to post-disciplinary hearing cautious decisions were not only due to new information but also to information being perceived as credible. Reports of disciplinary hearings of one school studied indicated that credible information resulted in shifts on the bases of type of disciplinary problem, the behaviour characteristics of the offender and the effect of the disciplinary problem on the victim. For instance, a disciplinary problem involving a boy threatening other students with knives and other dangerous weapon was reported. Because this behaviour problem impacted negatively on the safety and security of the school, students were badly affected. The predisciplinary hearing decisions of many members were risky as the behaviour problem was considered criminal act and that the boy should be handed over to the police. At the disciplinary hearing, the offending student was observed to be abnormal in his behaviour. Rather than hand over the student to the police, the panel members decided to recommend him for psychiatric treatment when it was certain and based on the opinion of an expert that the boy would benefit from such treatment.

An excerpt from interview transcripts reflecting the views of a participant is as follows:

My decision before the panel meeting was that the boy should be suspended because I thought that the boy issued threats when in a normal state of mind. My decision changed during the disciplinary hearing when he was brought and the evidence clearly showed from his unique behaviour and from expert's opinions of psychologist and psychiatrist that he was not fine. I was persuaded to change my decision that the boy could not be punished but that he should be referred to as psychologist or psychiatrist.

The participants of the study also reported sources of credible information as experts, eye witnesses, respected members of the school or public and even parents when they are perceived to be given true information and not necessarily to protect or defend their children. Shifts in decisions were also reported to happen when the information givers at disciplinary hearings were older and more experienced in teaching. Older and more experienced panel members are respected for their ages. Older members from their wealth of experiences in treating disciplinary problems in schools are often seen to provide disciplinary panels with opinions which often lead to members shifting from their predisciplinary hearing decisions to post-disciplinary hearing decisions.

For instance, a boy accused of alcohol abuse and violent behaviour appeared before a school's disciplinary hearing. Before the disciplinary hearing, the panel members were of the opinion that alcohol abuse and violent behaviours like fighting are unacceptable behaviours as these make the learning environment of the school unsafe, negatively impact on the image of the school as well as having negative effects on the health and academic development of students. The pre-disciplinary hearing decisions were therefore risky or extreme as panel members saw it fit to uphold the zero tolerance of such behaviour. However, during disciplinary hearing, information was provided to the effect that the student involved was a final year student. Older members of the panel felt that applying extreme sanction on the student could completely destroy him as he might not be able to write the final examination and graduate from the school. The older members persuaded the panel members to opt for a decision that will not lead the student jeopardizing the final examination, for example, holding on to his certificate until he has served punishment before releasing it. The student was also made to sign an undertaking to be of good behaviour while he was also reported to his parents. Considering this problem, the younger panel members reported that their decisions shifted when they were persuaded by the older members of the panel to adopt decisions that would not destroy the student but serve to reform him and give him another chance in life.

An excerpt from interview transcripts reflecting the view of a younger participant is as follows:

My decision changed during the disciplinary hearing meeting because the older members indicated that the time was critical to the boy because he was to do his final examinations and therefore making him stay out of school due to 
suspension would even destroy his life completely, and that he may even decide to drop out of school and abandon exams altogether. I realized that the older members were of the opinion of sending the student for counseling and monitoring the student closely during the examinations period so that he could complete schooling and I regarded their decision as more wise in taking care of the students circumstances.

The findings on shifts from pre-disciplinary risky to post-disciplinary cautious decisions agree with those of Nordhoy, (1962); and Stoner, (1968), the group effects were not consistent for all the 12 items used by Stoner. A review of results presented from Stoner's thesis indicated that, on one item that dealt with marriage, Stoner"s subjects were consistently more cautious in their post-group decisions. The findings, based on studies carried out by other researchers such as Rabow, et al, (1966) and Stoner, (1968), have reported that groups shift toward cautious decisions. From the persuasive arguments theoretical perspective, groups tend to bring up and repeat shared information (information that most members possess) at the expense of raising other potentially important hidden information that only a few members have. However, persuasive arguments may also make groups fall prey to information bias when confronting hidden profile situations, leading to more extreme (and often impaired) decisions (Kugler, et al, 2012). Negative effect of persuasive argument may be when a source of information or opinion considered to be persuasive over-emphasizes certain aspects of an issues being discussed by a group at the expense of other aspects. Group decisions emanating from such over-emphasis could be when group members are deeply involved in a cohesive in-group or when group members' striving for unanimity override their motivation to realistically appraise other aspects of issue being discussed by a group of alternative courses of action (Schoenfeld, 2011). Boateng (2012) described such phenomenon as "group think" a mode of action thinking in a group that happens when the desire for harmony in a decision making overrides realistic appraisal of alternatives. Consequences of the psychological phenomenon of "group think" often results in group decisions which may not receive wide acceptance or support. Participants of this study reported cases where panel decisions were rejected when such decisions were considered as emanating from panel members desire for solidarity among themselves and not necessarily from critical assessment of issues around student behaviour problems involved. This, therefore, means that there should be some form of check and balance in the operations of school disciplinary panels in order to avoid inaccurate decisions that may occur from negative effects of persuasive arguments.

The school disciplinary panel members used persuasive arguments from other group members that support their position as a means of rational construction, and at the same time they engage in social comparison to make decisions concerning student behaviour problems. The decisions arrived at after persuasive arguments could be of higher quality because the panel members have considered all the factors associated with the disciplinary problems. The goal of the disciplinary panels is to enhance the behaviour development of students, and this can only be achieved through making good decisions. Good decisions regarding students' behaviours lead to good recommendations as to interventions in behaviour problem situations. The diversity in the members of panels contribute to richness in discussions and good quality decisions because there are a variety of ideas hence, the possibility of new information to bring better understanding or better comprehension and decision. Rokou, et al, (2011) note that group decisions make the most of the combined individual abilities, knowledge and expertise of the group members.

\section{Concluding Remarks}

The purpose of this study was to find out whether persuasive arguments influenced group polarization in decision making behaviours among members of selected Kenyan secondary school disciplinary panels. The study revealed that persuasive arguments influenced group polarization, that is, shift from pre-disciplinary hearing decisions to postdisciplinary hearing group decisions among members of Kenyan secondary school panels. Persuasive arguments were found to have influenced group polarization in disciplinary processes of disciplinary hearings also speak to the significance of this study for providing useful information on policy decisions regarding behaviour management of student in schools. The study recommends that there is need to give consideration to composition of broad based disciplinary panels. By broad base it is meant that members of a school disciplinary panel should reflect the demographic composition of all stakeholders, and that, teachers should not be the only members making up a school disciplinary panel. While it is recognized that teachers are more in contact with student behaviour problems in schools, the school is not and cannot be the only place where solution to student behaviour problems should be procured. Moreover, since the homes and communities also have stakes in what happen to students in schools members of homes and communities must also be allowed to have a say in what happens in school. Decisions from such broad base panels are more likely to be perceived as more rational and fair and more likely to attract the confidence and acceptance of the general public. Broad - based disciplinary panels also make for check and balances and to avoid the adverse consequences of the psychological phenomenon of "group think" on disciplinary panel decisions. 
One limitation of the study was that, some disciplinary panel members were rather cautious in giving certain information, while others may not have completed or responded to the instrument appropriately. This was brought to the surface when conducting interviews with selected panel members, and some participants appeared to be restrained to disclose certain information concerning their schools. This may have affected the information gathered for this study, but it is believed that assurance given of the confidentiality of information and the fact that participation was voluntary, may have resulted in most of the respondents providing valuable accurate information for the study. One recommendation for further research is that, there is need to investigate how personality characteristics of panel members influence persuasive arguments during disciplinary hearings.

\section{Acknowledgements}

The writing of this article has been supported by University of the Western Cape Writing Fellowship.

\section{References}

Albarracina, D., Wallaceb, H. M., Hartc, W., \& Brownd, R. D. (2012). How judgments change following comparison of current and prior information. Basic and Applied Social Psychology, Volume, 34 (1), 44-55. doi/abs/10.1080/01973533.2011.637480.

Aloka, P.J.O. (2012). Group polarization in decision making: a study of selected secondary school disciplinary panels in Rongo district of Kenya. Unpublished PhD thesis, Faculty of Education, University of the Western Cape, Cape Town, South Africa.

Aloka, P.J.O. \& Bojuwoye, (2013).Gender, age and teaching experiences differences in decision-making behaviours of members of selected Kenyan secondary school disciplinary panels. Asian Social Science, Volume 9 (10), 43-55. doi:10.5539/ass.v9n10p43.

Andrews, S. P., \& Taylor, P. B. (1998). Evaluation of an alternative discipline program. High School Journal, 81(4), 209-217.

Belbin, R. M. (2010). Team roles at work (2nd edition). Butterworth: Heinemann.

Boateng, W. (2012). Evaluating the efficacy of focus group discussion (FGD) in qualitative social research. International Journal of Business and Social Science, Volume, 3(7), 54-57.

Bojuwoye, O., \& Akpan, O. (2009). Personal, familial and environmental perspectives in children's reactions to parental divorce in South Africa. Journal of Family Studies, 15(3), 260-273.

Durlak, J. A., Weissberg, R. P., Dymnicki, A. B., Taylor, R. D., \& Schellinger, K. B. (2011). The impact of enhancing students" social and emotional learning: A meta-analysis of school-based universal interventions. Child Development, Volume, 82 (1), 405-432. doi: 10.1111/j.1467-8624.2010.01564.x.

Hinshaw, S. (1992). Externalizing behaviour problems and academic underachievement in child-hood and adolescence: Casual relationships and underlying mechanisms. Psychological Bulletin, 111, 127-155.

Joubbert, R., de Waal, E., \& Rossouw, J. P. (2004). Discipline: Impact on access to equal educational opportunities. Perspectives in Education, Volume $22(3), 77-87$.

Kim, D., \& Park, J. (2010). Cultural differences in risk: The group facilitation effect. Society for Judgment and Decision Making, Volume, 5 (5), 380-390. Retrieved from: http://journal.sjdm.org/10/91115/jdm91115.pdf

Klein, T., \& Olbrecht, M. (2011). Triangulation of qualitative and quantitative methods in panel peer review research. International Journal for CrossDisciplinary Subjects in Education (IJCDSE), Volume 2(2), 342-348. Retrieved from: http://www.wissenschaftsmanagementonline.de/converis/artikel/1585.

Mason, M. (2010). Sample size and saturation in PhD studies using qualitative interviews. Forum Qualitative Sozial for schung / Forum: Qualitative Social Research, 11(3), Art. Retrieved April 10th, 2012, from http: //nbn- resolving.de/urn:nbn:de:0114-fqs100387.

Mercier, H., \&Sperber, D. (2011). Why do humans reason? Arguments for an argumentative theory. Behavioural and Brain Sciences, Volume, 34, 57 -111. doi:10.1017S0140525X10000968.

Nordhoy, F. (1962). Group interaction in decision-making under risk. Published Thesis, MIT School of Industrial Management.

Rokou, E., Voulgaridou, D., \& Kirytopoulos, K. (2011). Web based group decision making in human resources management. Proceedings of the International Symposium on the Analytic Hierarchy Process, 2011. http://204.202.238.22/isahp2011/dati/pdf/137_081_Rokou.pdf.

Schoenfeld, A. H. (2011). How we think: A theory of goal-oriented decision making and its educational applications. New York, NY: Routledge. DOI: 10.1080/10986065.2012.683320.

Soll, J. B., \& Larrick, R. P. (2009). Strategies for revising judgment: How (and how well) people use others' opinions. Journal of Experimental Psychology, $35,780-805$.

Sprinthal, N. A. (1980). Guidance and new education for school. Personnel and Guidance Journal, 58(7), 485-489.

Squelsh, J. M. (2000). Discipline. Pretoria: CELP.

Stevens, J. (1992). Applied multivariate for the social sciences (2nd edition). Hillsdale: Erlbaum Associates.

Stoner, J. A. F. (1961). A comparison of individual and group decisions involving risk. Published Thesis, Massachutes Institute of Technology, U. S. A.

Stoner, J. A. F. (1968). Risky and cautious shifts in group decisions. Journal of Experimental Social Psychology 4, 442-59.

Straus, S. G., Parker, A. M., \& Bruce, J. B. (2011). The group matters: A review of processes and outcomes in intelligence analysis. Group Dynamics: Theory, Research, and Practice, Volume, 15(2), 128-146. DOI:10.1037/a0022734.

Tajeddin, G., Safayeni, F., \& Connelly, C. E. (2012). The influence of emergent expertise on group decision processes. Small Group Research, Volume, 43(1), 50-74. doi: 10.1177/1046496411418251.

Wayne, N. L. (2011). Persuasive message effects on individuals versus interacting groups. Unpublished Thesis in Psychology at the Texas Tech University, USA. Retrieved from http://hdl.handle.net/2346/13427 on 28th October, 2013.

Zhu, H. (2009). Group polarization on corporate boards: Theory and evidence on board decisions about acquisition of premiums, executive compensation, and diversification. Journal of Operations Management, Volume, 27(6), 495-511.

Zorn, T. E., Roper, J., Broadfoot, K., \& Weaver, K. (2006). Focus groups as sites of influential interaction: Building communicative self-efficacy and effecting attitudinal change in discussing controversial topics. Journal of Applied Communication Research Volume, 34(2), 115-140.

Zuber, J. A., Crott, H. W., \& Werner, J. (1992). Choice shift and group polarization: An analysis of the status of arguments and social decision schemes. Journal of Personality and Social Psychology, Volume 62(1), 50-61. 